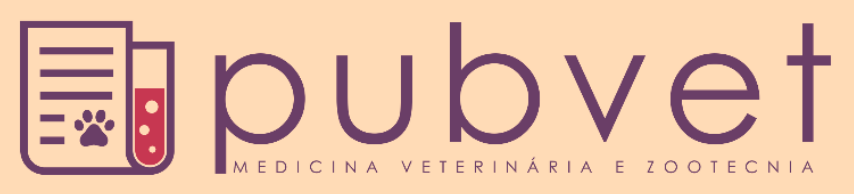

https://doi.org/10.31533/pubvet.v13n1a256.1-4

\title{
Anaplasma platys em cadela de pequeno porte: Relato de caso
}

\author{
Bruna Pinheiro Feitosa ${ }^{1 *}$, Ana Carolina Ramos Silva ${ }^{2}$, Khayla Bianka Alves Rodrigues ${ }^{2}$, \\ Raíssa Drielle Freitas Franco ${ }^{20}$
}

${ }^{1}$ Graduanda de Medicina Veterinária da Universidade Federal do Tocantins, Campus EMVZ, Araguaína-TO Brasil. ${ }^{2}$ Graduanda de Medicina Veterinária da Universidade Federal do Tocantins, Campus EMVZ, Araguaína-TO Brasil. *Autor para correspondência, E-mail: bp.feitosa@hotmail.com

Resumo. Uma cadela de pequeno porte, sem raça definida, pesando 3,650kg, com 3 meses de idade, foi atendida no Hospital Veterinário da Escola de Medicina Veterinária da Universidade Federal do Tocantins com histórico de apatia, anorexia, hiporexia, urina normal quanto ao volume, aspecto e frequência, e diarreia líquida com coloração amarelada. Ao exame físico observou: baixa temperatura do animal (hipotermia), quadro de desidratação discreta (elasticidade da pele discreta), estado geral com comportamento apático e perda de peso. Diagnosticado com Anaplasma platys após realização de exame parasitológico, o animal foi submetido a tratamento apresentando melhora durante acompanhamento.

Palavras chave: trombocitopenia, apatia, cadela

\section{Anaplasma platys in small dog: Case report}

Abstract. A 3-month-old, 3-year-old, small-bred dog weighing 3,650 kg was seen at the Veterinary Hospital of the Veterinary School of the Federal University of Tocantins with a history of apathy, anorexia, hyporexia, appearance and frequency, and liquid diarrhea with yellowish coloration. On physical examination he observed: low temperature of the animal (hypothermia), picture of discreet dehydration (elasticity of the discreet skin), general state with apathetic behavior and loss of weight. Diagnosed with Anaplasma platys after parasitological examination, the animal was submitted to treatment and showed improvement during follow-up.

Keywords: thrombocytopenia, apathy, female dog

\section{Anaplasma platys en perra de pequeño porte: Relato de un caso}

Resumen. Una hembra canina de pequeño porte, mestiza, con peso de 3,650 kg, 3 meses de edad, fue atendida en el Hospital de la Escuela de Medicina Veterinaria de la Universidad Federal do Tocantins con histórico de apatía, anorexia, pérdida de apetito, orina normal, cuanto, al volumen, aspecto y frecuencia, y diarrea líquida con coloración amarillenta. Durante el examen físico se observó: baja temperatura del animal (hipotermia), cuadro de deshidratación discreta (elasticidad de la piel discreta), estado general con comportamiento apático y pérdida de peso. Diagnosticado con Anaplasma platys después de la realización de examen parasitológico, el animal fue sometido a tratamiento presentando mejoría durante el seguimiento.

Palabras clave: trombocitopenia, apatía, hembra canina 


\section{Introdução}

A trombocitopenia cíclica canina é causada pelo Anaplasma platys (antigamente E. platys) um microrganismo bacteriano que se multiplica apenas em plaquetas (Birchard \& Sherding, 2008) são microrganismos da ordem Rickettssiales e gram-negativos (Ettinger \& Feldman, 2004). Pertencem a família Anaplasmataceae. Presume-se que A. platys seja transmitido por carrapato, mas as espécies de carrapatos específicas não são conhecidas (Birchard \& Sherding, 2008). A. platys parece ser minimamente patogênico e, na maior parte dos cães, não ocasiona sinais clínicos (Birchard \& Sherding, 2008). Após a inoculação intravenosa, o período de incubação é de 8 a 15 dias. Embora a trombocitopenia cíclica e a parasitemia possam ocorrer em intervalos de 10 a 14 dias, o número de organismos e a gravidade da trombocitopenia podem diminuir ao longo do tempo (Nelson \& Couto, 2015).

A anaplasmose trombocitotrópica canina possui como sinais clínicos mais comuns a anorexia, letargia, perda de peso, depressão. Sinais de hemorragia espontânea são raros (Birchard \& Sherding, 2008). Pode ocorrer discreta anemia arregenerativa normocítica normocrômica, leucopenia, hipoalbuminemia e hiperglobulinemia. O diagnóstico baseia-se em exames sorológicos, PCR ou exame citológico do sangue (Ettinger \& Feldman, 2004). Anticorpos séricos podem ser detectados por IFA (Nelson \& Couto, 2015). Sorologicamente, A. platys não exibe reação cruzada com E. canis, A. phagocytophila ou N. risticii (Birchard \& Sherding, 2008). Segundo Nelson \& Couto (2015), a PCR realizada a partir de sangue coletado em ácido etilenodiamino tetra-acético (EDTA) pode ser utilizada para confirmar a infecção e diferenciar a infecção por A. platys de outras infecções; e o DNA microbiano também pode ser amplificado a partir de cães saudáveis (Kordick et al., 1999) e pode ser negativo em cães clinicamente doentes (Eddlestone et al., 2007).

O tratamento com tetraciclina $(22 \mathrm{mg} / \mathrm{kg}$ a cada oito horas durante 14 dias $)$ ou, presumivelmente, com doxiciclina (5 mg/kg a cada 12 horas durante 14 dias) por via oral deve eliminar o microrganismo (Ettinger \& Feldman, 2004). O prognóstico depende do estágio em que se encontra a doença e quando o tratamento foi ou será instituído, sendo que o prognóstico é bom com um tratamento adequado.

O objetivo deste trabalho foi relatar o tratamento clínico do Anaplasma platys e a consequente evolução do animal.

\section{Relato de caso}

Foi atendido no Hospital Veterinário da Universidade Federal do Tocantins, no dia 21 de junho de 2016, uma cadela, fêmea, pesando $3,65 \mathrm{~kg}$ possuindo cerca de 3 meses de idade, porte pequeno, sem raça definida e impúbere. Durante a anamnese o proprietário relatou que há aproximadamente 24 horas o animal começou a apresentar um quadro de diarreia liquida com coloração amarelada, urina normal quanto ao volume, aspecto e frequência, falta de apetite (hiporexia), perda de peso, anorexia, sem alteração da sua alimentação anterior e apatia. Proprietário afirmou desatualização na vermifugação. Ao exame físico, notou-se frequência cardíaca a 168 batimentos por minuto (bpm), frequência respiratória de 28 movimentos por minuto de forma regular, pulso médio, tempo de preenchimento capilar (TPC) de 2 segundos, desidratação discreta até $5 \%$, mucosas normocoradas, presença de sons de capoteio durante palpação abdominal e temperatura de $35,5^{\circ} \mathrm{C}$.

Após realização do exame físico, o animal foi encaminhado para internação onde foi realizada coleta

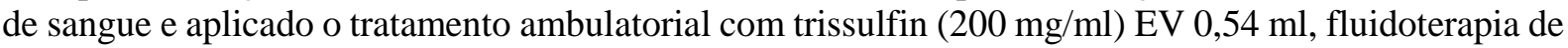
manutenção (ringer com lactato $500 \mathrm{ml}$ ), glicose $50 \% 10 \mathrm{ml}$ e vitamina B12 $1 \mathrm{ml}$. Os exames complementares solicitados foram: hemograma e pesquisa de hemoparasitas. $\mathrm{O}$ animal foi liberado para casa após considerável melhora somente com a terapia ambulatorial. No dia seguinte com o retorno ao Hospital Veterinário, o proprietário relatou episódio de vomito sofrido pelo animal, o mesmo foi novamente internado e medicado com cerenia $(0,1 \mathrm{ml} / \mathrm{kg}) \mathrm{SC} 0,365 \mathrm{ml}$, ranitidina $(1-2 \mathrm{ml} / \mathrm{kg}) \mathrm{SC} 0,21$ $\mathrm{ml}$ e fluidoterapia de manutenção (ringer com lactato $500 \mathrm{ml}$ ).

$\mathrm{O}$ resultado do exame laboratorial no caso do hemograma realizado em laboratório humano demonstrou anemia normocítica. No exame complementar de pesquisa de hemoparasitas foram observadas formas sugestivas de Anaplasma platys na amostra de esfregaço sanguíneo examinada. 
Com a melhora do quadro clínico e diagnóstico concluído o animal recebeu alta com a prescrição de doxiciclina (100 mg/kg, um a quatro comp/cada 12 horas/30 dias), estimulante de apetite hemolitam (1 $\mathrm{ml} / \mathrm{cada} 12$ horas/30 dias). Com o diagnóstico e a instituição do tratamento realizado, o animal possuiu um bom prognóstico.

\section{Discussão}

De acordo com os sinais clínicos e exames realizados foi sugerido como diagnóstico de infecção por Anaplasma platys causando a chamada trombocitopenia cíclica canina, sendo essa denominação devido ao fato que após a infecção, em alguns dias ocorre uma diminuição brusca no número de plaquetas com o agente etiológico desaparecendo da circulação. Como descrito por Ettinger \& Feldman (2004), no ponto mais baixo (de 20.000 a 50.000 plaquetas $/ \mu \mathrm{L}$ ) a trombocitopenia pode ser grave e as plaquetas estão hipo-agregáveis. Em um período de aproximadamente quatro dias após o episódio de diminuição plaquetária o nível de plaquetas sofre um retorno próximo aos seus valores de referência com a parasitemia e trombocitose seguintes ocorrendo em intervalos de 10 a 14 dias.

O hemograma solicitado teve sua realização em laboratório humano o que pode induzir a erro na interpretação e definição do diagnóstico, pois existem diferenças entre as espécies como na morfologia celular e nos valores de relação. O exame encontrou para VCM e CHCM valores de 64,64 e 32,93 respectivamente onde os valores de referência são de 60 - 70 para o primeiro e 32 - 36 para o segundo. Os valores encontrados confirmam um quadro de anemia normocítica normocrômica, como relatado por Birchard \& Sherding (2008). O aparecimento de leucopenia na análise laboratorial condiz com os descritos por Birchard \& Sherding (2008) e Ettinger \& Feldman (2004).

McGavin \& Zachay (2013) descreveram que a trombocitopenia resulta de aumento da destruição plaquetária, o que diverge do encontrado na análise feita em laboratório. O exame relata um total de 541.000 plaquetas onde o valor referencial é de 200.000 a $500.000 / \mathrm{mm}^{3}$ demonstrando assim um aumento no nível plaquetário. Esse aumento na contagem das plaquetas pode ser devido a: ao resultado errático em consequência da realização do exame em laboratório humano, como já discorrido anteriormente; ocorrência de "trombocitose de rebote" devido à recuperação da trombocitopenia onde acontece uma estimulação excessiva da trombopoiese elevando a concentração das plaquetas durante a recuperação, como descrito por Stockham \& Scott (2011); aumento trombopoiese em caso de inflamação, a mesma estimula o aumento do número e tamanho dos megacariócitos juntamente com o aumento de plaquetas ou recuperação do processo inflamatório onde a IL-6 um de seus precursores provoca aumento das plaquetas que se encontravam baixas.

Como diagnóstico foi realizado o exame citológico do sangue isoladamente tornando esse método de diagnóstico pouco sensível o que é afirmado por Birchard \& Sherding (2008). Para um resultado com pouca margem de erro é necessário realização exames sorológicos como IFA tendo o cuidado de não ocorrer reação cruzada com A. phagocytophilum ou molecurares como PCR que possui maior sensibilidade e especificidade quando comparado a reação de imunofluorescência indireta.

Para o tratamento de A. platys o fator limitante é o fato de o agente possuir localização intraplaquetária, portanto as tetraciclinas como a doxiclina são as mais eficazes para o tratamento.

\section{Conclusão}

O caso clínico serviu como amostra da importância e boa análise do quadro físico e geral do animal conjuntamente com a realização dos exames laboratoriais para se chegar em um diagnóstico, definir e aplicar o tratamento correto a fim de alcançar a melhora do animal. As alterações encontradas com a realização dos exames demonstraram divergência com o comum de se encontrar no caso de trombocitopenia cíclica canina. Os usos das terapias ambulatoriais e prescritas alcançaram o objetivo inicial de melhoria da qualidade de via do animal proporcionando assim um bom prognóstico para o paciente.

\section{Referências bibliográficas}

Birchard, S. J. \& Sherding, R. G. (2008). Manual Saunders: clínica de pequenos animais (Vol. 3). São Paulo Roca, 2072p. 
Eddlestone, S. M., Diniz, P. P. V. P., Neer, T. M., Gaunt, S. D., Corstvet, R., Cho, D., Breitschwerdt, E. B. (2007). Doxycycline clearance of experimentally induced chronic Ehrlichia canis infection in dogs. Journal of Veterinary Internal Medicine, 21(6), 1237-1242.

Ettinger, S. \& Feldman, E. (2004). Tratado de medicina interna veterinária: doenças do cão e do gato. Rio de Janeiro: Guanabara Koogan, 2256p..

Kordick, S. K., Breitschwerdt, E. B., Hegarty, B. C., Southwick, K. L., Colitz, C. M., Hancock, S. I., . MacCormack, J. N. (1999). Coinfection with multiple tick-borne pathogens in a Walker Hound kennel in North Carolina. Journal of Clinical Microbiology, 37(8), 2631-2638.

McGavin, D. \& Zachay, J. F. (2013). Bases da patologia em veterinária. São Paulo: Elsevier Brasil.

Nelson, R. W. \& Couto, C. G. (2015). Medicina interna de pequenos animais. Amsterdan: Elsevier Editora.

Stockham, S. L. \& Scott, M. A. (2011). Fundamentos de patologia clínica veterinária (Vol. 8). Rio de Janeiro.

Recebido: 13 outubro, 2018

Aprovado: 10 novembro, 2018

Publicado: 23 janeiro, 2019

Licenciamento: Este artigo é publicado na modalidade Acesso Aberto sob a licença Creative Commons Atribuição 4.0 (CC-BY 4.0), a qual permite uso irrestrito, distribuição, reprodução em qualquer meio, desde que o autor e a fonte sejam devidamente creditados 